\title{
William Kaelin, Peter Ratcliffe, and Gregg Semenza receive the 2016 Albert Lasker Basic Medical Research Award
}

$T$ ation has been recognized for over 200 years, but how cells and tissues are able to monitor and respond to oxygen levels remained elusive until the late twentieth century. The 2016 Albert Lasker Basic Medical Research Award honors three scientists (Figure 1), William Kaelin, Peter Ratcliffe, and Gregg Semenza, for the discovery of the molecular mechanisms by which human and animal cells sense and respond to low or inadequate oxygen levels, referred to as hypoxia.

Molecular oxygen is a critical substrate for cellular metabolism and bioenergetics, and cells within each tissue require an adequate oxygen supply to meet the needs of these pathways, as either oxygen deficiency or excess can lead to rapid death of both cells and whole organisms. While organisms with just a few cells can rely on passive oxygen diffusion, large multicellular organisms require multiple complex organ systems, including respiratory, circulatory, and neuroendocrine systems, to ensure that all cells and tissues have reliable access to oxygen. In all cells and tissues, hypoxia initiates a series of physiological responses that are geared toward maintaining oxygen homeostasis over a time course of minutes to days. These events include upregulation of processes that enhance oxygen delivery, such as erythropoiesis, angiogenesis, and modulation of vascular tone, and downregulation of oxygen consumption through changes in cellular metabolism, proliferation, and apoptosis. Importantly, these adaptive responses are dysregulated in a number of disease states. Thus, the identification of the pathways that sense and respond to oxygen levels has not only furthered our understanding of multiple developmental and physiological processes, but has also opened up new avenues for the development of therapies to treat diseases such as anemia, cardiovascular disease, pulmonary hypertension, stroke, and cancer.

\section{Early evidence of an oxygen sensor}

As anyone who has traveled at high altitudes will attest, low levels of atmospheric oxygen have marked effects on the 1910 Anglo-American expedition to Pikes Peak to investigate the effects of high altitude on breathing, Mabel Fitzgerald found that signs and symptoms of the response of humans to high altitude were set off even by small reductions in the partial pressure of oxygen $\left(\mathrm{pO}_{2}\right)$ in the arterial blood $(2,3)$.

Further support for an oxygen-sensing mechanism was provided by the


Figure 1. The recipients of the 2016 Albert Lasker Basic Medical Research Award. From left to right: William Kaelin, Peter Ratcliffe, and Gregg Semenza discovered the essential pathway by which human and animal cells sense and adapt to changes in oxygen availability. Image credits (left to right): Sam Ogden/Dana-Farber Cancer Institute, Paul Wilkinson Photography, Jay VanRensselaer/ Johns Hopkins Medicine.

physiology, ranging from relatively mild symptoms, such as breathlessness and dizziness, to severe symptoms, such as pulmonary and cerebral edema. Consequently, some of the earliest evidence for an oxygen-sensing mechanism in animal cells came from scientists visiting high-altitude locales. In 1890, François-Gilbert Viault noted that the number of erythrocytes in his blood was elevated after a stay in the Peruvian highlands (around 4,500 $\mathrm{m}$ above sea level). He concluded that erythropoiesis is stimulated when blood oxygen content is reduced (1). Similarly, as part of discovery of erythropoietin (EPO), a glycoprotein hormone that stimulates erythrocyte production. In adults, EPO is produced in response to low oxygen levels in the blood by interstitial fibroblasts in the renal cortex. Human EPO was purified in 1977 (4), followed by cloning of the human EPO gene in 1985 $(5,6)$. These advances led to the development of recombinant human EPO for the treatment of anemia; however, the mechanisms underlying the regulation of EPO by oxygen levels remained enigmatic.

By the end of the 1980s, it was well established that the kidneys controlled the number of erythrocytes and thus the oxygen capacity of the blood through the release of EPO (7). Further, it was known 
that EPO production had three critical regulatory properties: 1) EPO expression is tissue specific; 2) EPO exhibits developmental stage specificity, being produced prenatally in the fetal liver, then postnatally in the kidney; and 3) EPO expression is inducible, with expression increasing in response to hypoxia, anemia, or cobalt chloride exposure (8-12). These properties attracted the attention of two researchers, Gregg Semenza and Peter Ratcliffe, who would soon demonstrate that EPO is not the only gene regulated by hypoxia.

\section{A genetic hypoxia response element}

In 1986, Gregg Semenza was a postdoctoral fellow in medical genetics at Johns Hopkins School of Medicine, working with research teams led by Haig Kazazian and Stylianos Antonarakis, who were renowned for their ability to dissect disease-associated mutations in order to understand how these mutations affected gene expression. "At the time, I was interested in studying developmental regulation, and it was known that EPO is expressed in the fetal liver and then in the adult kidneys. The original goal was to figure out what sequences were regulating the expression in different organs during development," Semenza recently recounted to the JCI. At the time, the ability to create transgenic animals was relatively new, but this technique had the advantage of allowing direct manipulation of various aspects of gene expression, making it an interesting model in which to study the regulation of EPO. In a collaboration with John Gearhart, Semenza engineered transgenic mice carrying human EPO. The transgenic mice exhibited increased erythropoiesis compared with their wild-type counterparts. (13). Semenza next began expressing EPO constructs that contained additional $5^{\prime}$ or 3 ' flanking regions to demonstrate that these regions conferred tissue-specific and hypoxia-inducible expression $(14,15)$. Narrowing down the hypoxia-responsive region of the EPO gene, Semenza identified a region downstream of the EPO coding sequence that was bound by multiple nuclear factors. The addition of this region to a different gene construct conferred hypoxia-inducible expression (16).
During the same time period in which Semenza was developing EPO-transgenic mice, Peter Ratcliffe, a physician and kidney specialist, was establishing a laboratory in Oxford University's Nuffield Department of Medicine to study the regulation of EPO, a venture that was to be strongly supported by Christopher Pugh, Patrick Maxwell, and other kidney specialists training at Oxford at the time, who contributed much to the laboratory's work. As a kidney specialist, Ratcliffe was initially intrigued by the unusual counter-current circulation within the kidney that results in very low oxygen tensions within specific areas of the organ. "Somewhat surprisingly, the kidney is able to distinguish changes in blood oxygen content and the numbers of red blood cells in circulation from changes in renal blood flow. Consideration of this remarkable oxygen-sensing capacity was what initially led me into the field," said Ratcliffe. By understanding how oxygen regulated EPO production, it would be possible to get at the oxygen-sensing mechanism in the kidney. One of Ratcliffe's early experiments demonstrated that Epo mRNA levels in isolated rat kidneys were responsive to changes in oxygen delivery, confirming that all of the components necessary for Epo regulation were present in the kidney (17). At the time, there was evidence that diseased kidneys and extrarenal tissues could produce EPO, but the extent and localization of EPO production were unclear. Using very sensitive assays, Ratcliffe and colleagues showed that Epo mRNA was detectable not only in the kidneys and livers of rats, but also that small amounts of Epo mRNA became detectable in the spleen, brain, and testes under hypoxic conditions, indicating that hypoxia can induce EPO expression outside of the kidney and suggesting that the oxygen-sensing process operated more widely than had previously been considered $(18,19)$. In a parallel line of investigation testing hypoxia-inducible expression of truncated forms of the mouse Epo gene, Ratcliffe identified a region downstream of the coding sequence that was required for oxygen-regulated expression (20). By coupling this region of murine Epo to a broadly active promoter in cell lines derived from different tissues, Ratcliffe demonstrated that oxygen sensing was possible in many different cell types, even in those that did not produce EPO, suggesting that similar oxygen-sensing mechanisms were involved in the regulation of other genes (21-23).

The identification of a genetically encoded hypoxia response element (HRE) and the demonstration that this element could be activated in a variety of tissues opened up two new avenues of research: 1) the identification of the nuclear factors that regulate hypoxia-induced gene expression and 2) the identification of other genes that respond to hypoxia through similar mechanisms.

\section{A hypoxia-inducible transcription factor}

Semenza next focused on identifying the oxygen-regulated nuclear factors that bind EPO. In 1992, he and his postdoc, Guang Wang, identified the nuclear factor that bound the HRE, which they termed hypoxia-inducible factor-1 (HIF1). Moreover, HIF-1 binding of the HRE was required for transcriptional activation and was induced by hypoxia in a variety of mammalian cell lines (24). "No matter which mammalian cell line we looked at, if we exposed the cells to low oxygen for four hours, we saw the induction of HIF activity. So that was a pretty clear indicator that HIF-1 was not just regulating the expression of $E P O$, but was regulating the expression of other genes under hypoxic conditions," said Semenza. The DNA-binding activity of HIF-1 decayed rapidly when cells were exposed to increased oxygen levels, suggesting that HIF-1 activity itself was directly regulated by oxygen (25). It rapidly became clear that HIF was not restricted to mammalians cells, as the Ratcliffe group observed a similar activity in Drosophila cells around the same time (26).

Purification of HIF- 1 by the Semenza laboratory (27) revealed that it is a heterodimer consisting of an HIF-1 $\alpha$ subunit and an HIF-1 $\beta$ subunit (also known as aryl hydrocarbon receptor nuclear translocator [ARNT] protein), both of which are basic helix-loop-helix proteins that contain a Per-Arnt-Sim (PAS) domain. While HIF- $1 \beta$ expression is constitutive and stable, HIF-1 $\alpha$ protein is induced in 
cells exposed to $1 \%$ oxygen and decays rapidly when the cells are returned to normal oxygen levels $\left(21 \% \mathrm{pO}_{2}\right)$. The genes encoding HIF- $1 \alpha$ were assigned to murine chromosome 12 and human chromosome 14 in 1996 (28). The mRNAs encoding HIF- $1 \alpha$ and HIF-1 $\beta$ were present in all human, rat, and mouse organs tested (29). A closely related gene, $H I F 2 A$, was identified and cloned in 1997, followed by HIF3A in 1998 (3034). HIF-1 $\alpha$ homologs were subsequently found in other organisms, including Drosophila melanogaster and Caenorhabditis elegans, indicating an evolutionary conservation of the oxygen-sensing mechanism $(26,35-37)$.

The identification of the HIF proteins and cloning of the genes and cDNAs allowed for an in-depth functional analysis of the HIF subunits, providing hints as to how these genes and proteins are regulated. Studies in HIF- $1 \beta$-deficient cells by the Ratcliffe group demonstrated that this subunit was required for hypoxia-induced gene expression (38). Semenza's group showed that expression of a dominant-negative form of HIF-1 $\alpha$ blocked the transcriptional response to hypoxia (39). Semenza's group also identified the stretch of amino acids required for dimerization of the HIF- $1 \alpha$ and $-1 \beta$ subunits and DNA binding, as well as $\mathrm{N}$-terminal and C-terminal transactivation domains in HIF- $1 \alpha$ that interact with transcriptional coactivators such as CREB-binding protein (CBP), while both the Ratcliffe and Semenza groups identified a regulatory domain that prevents transcriptional activity in normoxic conditions (40-42). These regulatory domains would soon provide insights into the role of oxygen in the regulation of HIF activity.

\section{Identification of hypoxia- regulated genes}

Following the identification of the HRE and its operation in cell types that do not produce EPO, Ratcliffe and Semenza began hunting for other genes that exhibited hypoxia-induced expression. Both groups identified a number of genes involved in cellular metabolism, including human phosphoglycerate kinase-1 (PGK1), mouse lactate dehydrogenase-A (Ldha), mouse glucose transporter-1
(Glut1), human aldolase A (ALDA), enolase 1 (ENO1), and murine phosphofructokinase $(P f k l)$, which were bound and regulated by HIF-1 (43-46). Together, these studies established HIF-1 as a critical regulator of glycolysis, allowing cells to switch from aerobic to anaerobic metabolism (47).

Angiogenesis is critical for establishing a blood supply and is therefore also a means by which tissues can increase their oxygenation, making the process a likely HIF regulatory target. Ratcliffe's group showed that the expression of multiple angiogenic growth factors, including PDGFA/B, placental growth factor (PLGF), TGF- $\beta 1$, and VEGF, was regulated by hypoxia in a manner similar to that seen with EPO (48). This was followed by a study from the Semenza group demonstrating that the VEGF gene was directly transactivated by HIF-1 (39). Further, Semenza and colleagues engineered a mouse lacking both copies of Hifla, which resulted in developmental arrest and lethality at mid-gestation (E11) The HIF-1 $\alpha$-deficient embryos exhibited multiple malformations of the heart and blood vessels and decreased erythropoiesis (49). "Initially, the embryo is very small, and it can get all of its oxygen just from diffusion from maternal blood vessels," said Semenza. "At some point, it gets large enough that it has to have its own functioning circulatory system. When we looked at the expression of HIF- $1 \alpha$ in the embryo, we saw that at mid-gestation, the levels of HIF-1 $\alpha$ went up in the wild-type embryos, and that's when the mutant embryos died." These studies confirmed the role of oxygen homeostasis and HIF-1 in development. Identification of angiogenesis as a target of HIF-1 would quickly provide a link between HIF and another highly angiogenic process, tumorigenesis.

\section{The cancer connection: von Hippel-Lindau disease}

In 1993, William Kaelin, an oncologist, had just established his own laboratory after completing a postdoctoral fellowship focused on determining the functions of the retinoblastoma (RB) tumor suppressor in the laboratory of David Livingston at the Dana-Farber Cancer Institute. He was looking for a project that would be distinct from his postdoctoral work but that could potentially take advantage of some of the same experimental approaches he had used successfully to study RB. He then read a paper describing the identification of the gene that causes von Hippel-Lindau (VHL) disease (50), a familial cancer syndrome that predisposes affected individuals to hemangioblastomas in the CNS and retina, renal cell carcinoma, and pheochromocytoma, a benign tumor of the adrenal gland. From his clinical training, Kaelin knew that $V H L$ mutant-associated tumors are highly vascularized (angiogenic) and are notable for their ability to secrete EPO. By the early 1990s, there was considerable interest in targeting angiogenesis to treat tumors, making VHL-associated tumors a potentially useful system for the study of angiogenesis-targeted therapeutic approaches (51). In addition, he realized that a defect in oxygen sensing could be the unifying factor underlying the induction of angiogenesis and EPO by the VHL-mutant tumors, with the tumors behaving as though they were starved of oxygen. "These tumors are constantly putting out the stress signals that would be expected under hypoxic conditions. We thought that studying the VHL protein could provide some insight into how cells respond to hypoxia," said Kaelin.

Kaelin first demonstrated that VHL encodes a functional tumor suppressor (pVHL) (52), as reintroduction of wildtype, but not mutant, $V H L$ in a renal cell carcinoma line prevented the cells from forming tumors in mice. Further, his work, together with findings from Richard Klausner, indicated that pVHLmediated tumor suppression required that $\mathrm{pVHL}$ bind two proteins, elongins $\mathrm{B}$ and $\mathrm{C}$, originally identified as regulators of transcriptional elongation, but which are now known to wear multiple hats (53-55). The interactions between elongins $\mathrm{B}$ and $\mathrm{C}$ were disrupted by disease-associated $V H L$ mutations (53, 54, $56,57)$. Importantly, Kaelin showed that various hypoxia-inducible mRNAs, such as VEGF, GLUT1, and PDGFB, which had recently been shown to be regulated by HIF-1 (48, 58, 59), were insensitive to oxygen in renal cancer cell lines lacking pVHL and, consequently, were over- 
produced (60). In short, loss of pVHL uncoupled the accumulation of hypoxia-inducible mRNAs from actual oxygen availability.

The connection between HIF and cancer was also emerging. Using hepatoma-derived tumor xenografts, the Ratcliffe group demonstrated that VEGF and GLUT1 were induced in hypoxic regions surrounding areas of tumor necrosis in an HIF-1 $\beta$-dependent manner. Notably, HIF-1 $\beta$-deficient xenografts exhibited slower growth and reduced vascularization compared with HIF-1 $\beta$-expressing xenografts (61). Around the same time, the Semenza group demonstrated that the level of HIF-1 expression was correlated with tumor growth in murine xenografts (62). Further, Semenza's group found that HIF-1 $\alpha$ was overexpressed in multiple human cancers under both normoxic and hypoxic conditions (63), while Ratcliffe and his collaborators found that HIF- $1 \alpha$ and HIF- $2 \alpha$ were expressed in a number of human cancers and tumor-associated macrophages (64). Together, these studies suggested a broader role for HIFs in oncogenesis, as well as a potential connection to pVHL.

\section{Linking VHL and HIF}

Differences in $\mathrm{HIF} \alpha$ regulation at the protein and mRNA levels pointed to potential regulatory mechanisms. Lorenz Poellinger and colleagues found that HIF1A and HIF1B mRNAs are constitutively expressed under both normoxic and hypoxic conditions in transformed cell lines; in contrast, HIF $\alpha$ protein levels are highly sensitive to changes in oxygen levels, while HIF-1 $\beta$ protein levels are stable (65). These findings suggested that some form of posttranslational modification was responsible for regulating HIF- $1 \alpha$ levels. The Ratcliffe laboratory identified different domains of HIF- $1 \alpha$ that conferred oxygen-regulated activity, distinguishing domains that altered protein levels from others that did not. They also showed that oxygen-regulated activity persisted in one domain, even when all phospho-acceptor amino acids were mutated, directing attention away from protein phosphorylation as the signal transduction mechanism (41). A study by Jaime Caro demonstrated that HIF- $1 \alpha$ undergoes rapid ubiquitination and subsequent proteasomal degra- dation under normoxic conditions (66). Shortly thereafter, Frank Bunn and colleagues showed that HIF- $1 \alpha$ contains an oxygen-dependent degradation domain (ODD) consisting of approximately 200 amino acid residues that makes the protein unstable in the presence of oxygen and allows it to be degraded via the ubiquitin/proteasome pathway (67). The Semenza group then engineered missense mutations and deletions within HIF-10 that blocked ubiquitination, resulting in constitutive expression and transcriptional activity in normoxic conditions (68).

Structural analyses of the pVHL complex provided key support for a role in HIF- $1 \alpha$ degradation. Kaelin's group found that $\mathrm{pVHL}$-mediated regulation of hypoxia-inducible mRNAs required binding of $\mathrm{pVHL}$ to protein complexes containing elongins $\mathrm{B}$ and $\mathrm{C}$ and cullin 2 (CUL2) (69), a protein that was suspected to be involved in targeting proteins for ubiquitin-dependent proteolysis (70). Structural studies of the pVHL-elongin C-elongin B complex by Kaelin's collaborator Nikola Pavletich revealed that it is structurally similar to SKP1-CUL1-F-box protein (SCF) E3 ubiquitin ligases (57). This structure also showed that pVHL has two hotspots for VHL disease-associated mutations: the $\alpha$-domain, which Kaelin had shown is required for binding to the elongins and CUL2, and the $\beta$-domain, which was predicted to be a substrate docking site (57). Two additional observations increased the suspicion that the pVHL complex was an E3 ubiquitin ligase. First, Kaelin's collaborator Joan Conaway showed that the pVHL complex associates with ringbox 1 (RBX1), a known ubiquitin-conjugating enzyme (71). Second, two groups of researchers led by Richard Klausner and Wilhelm Krek showed that pVHL immunoprecipitated from cells displays E3 ubiquitin ligase activity $(72,73)$.

Soon thereafter, the Ratcliffe group demonstrated that cells lacking $\mathrm{pVHL}$ cannot target HIF-1 $\alpha$ for oxygen-dependent proteolysis in vivo (74). HIF $\alpha$ subunits were constitutively and stably expressed in VHL-defective cells, but reexpression of wild-type $\mathrm{pVHL}$ restored oxygen-dependent degradation of HIF $\alpha$. They also found that HIF $\alpha$ subunits and pVHL formed stable complexes in either normoxia or hypoxia, but that these complexes were disrupted by treatment with $\mathrm{Co}^{2+}$ or the iron chelator desferrioxamine. This observation initially led them to believe (as it turns out, erroneously see below) that an iron-requiring protein was essential for complex formation and could potentially be involved in oxygen sensing through a subsequent action. Subsequently, Kaelin's group showed that the pVHL-elongin B/C-CUL2 complex binds directly to the HIF-1 ODD domain and polyubiquitinates HIF- $1 \alpha$ (75). Similar conclusions were reached in parallel by the Ratcliffe, Poellinger, and Conaway laboratories and were published soon thereafter (76-78).

\section{An oxygen-dependent signaling mechanism}

The studies described above established that pVHL targets HIF $\alpha$ for ubiquitination and subsequent proteasomal degradation, but it was still unclear exactly how oxygen regulated this process. The Semenza group had shown that HIF was activated by $\mathrm{Co}^{2+}$ and iron chelators, as well as by hypoxia; these same factors induced the transactivation domain function of HIF $(42,79)$. These findings suggested the existence of an oxygenand iron-dependent modification governing the interaction of the HIF $\alpha$ ODD with pVHL. In April 2001, the Kaelin and Ratcliffe groups published independent back-to-back studies identifying proline hydroxylation as the crucial oxygen- and iron-dependent posttranslational modification of $\mathrm{HIF} \alpha$ that was required for recognition by the pVHL complex (80, 81); the same mechanism was identified by Frank Lee's group a few months later (82). Ratcliffe had initially been surprised when, as described above, they could isolate the HIF $\alpha$-pVHL complex from hypoxic cells, and postulated that reoxygenation of cell lysates during the experimental procedure might promote this interaction. "We made a slight mistake at the time, which is an interesting one," said Ratcliffe. "We initially thought that the association between VHL and HIF was regulated by cobalt and iron chelators, which matched the properties of the system, but not by oxygen. We were extremely puzzled by that, as normally those properties were all 


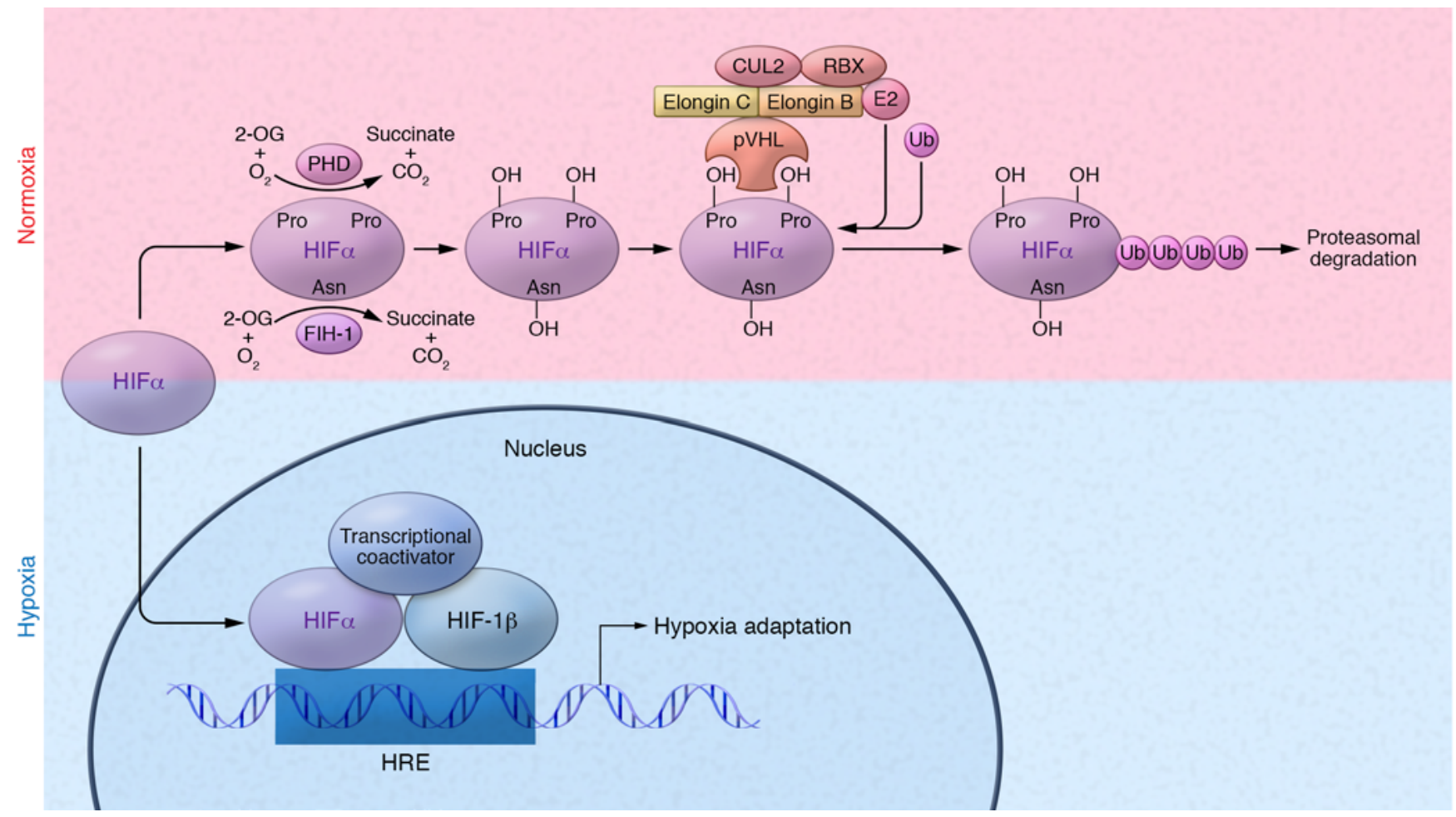

Figure 2. Regulation of hypoxia-inducible factors. Under normoxic conditions, two proline residues on the HIF $\alpha$ subunit are hydroxylated (OH) by PHD enzymes (PHD1, -2 , and -3 ), in the presence of $\mathrm{O}_{2}, \mathrm{Fe}^{2+}, 2-\mathrm{OC}$, and ascorbate (not shown). Hydroxylated $\mathrm{HIF} \alpha$ is recognized by the $\mathrm{pVHL}$ E3 ubiquitin ligase complex, which tags HIF $\alpha$ with polyubiquitin, allowing for proteasomal recognition and subsequent degradation. Additionally, the 2-OC dioxygenase FIH-1 hydroxylates an asparagine residue in the C-terminal transactivation domain of $\mathrm{HIF} \alpha$, preventing its interaction with transcriptional coactivators. Under hypoxic conditions, HIF $\alpha$ prolyl hydroxylation is inhibited, preventing recognition of HIF $\alpha$ by pVHL. HIF $\alpha$ can then accumulate and translocate to the nucleus, where it dimerizes with HIF-1 $\beta$. The HIF dimer binds to HREs within the promoters of target genes and recruits transcriptional coactivators such as CBP to induce transcription. Asn, asparagine; E2, ubiquitin-conjugating enzyme; Pro, proline; Ub, ubiquitin.

concordant. On reflection, we realized that oxygen would be in the buffers and all the reagents that we used to do the work on the bench. So it was possible that although the cells were made hypoxic, by the time we'd gotten the extracts, oxygen had gotten in, which turned out to be correct."

By repeating these experiments in a hypoxia workstation with deoxygenated buffers, two highly skilled postdocs in the Ratcliffe laboratory, Panu Jaakkola and David Mole, showed that the association between HIF $\alpha$ subunits and pVHL was governed by both oxygen and iron availability. Kaelin had reached the same conclusion by multiple means, including experiments with mouse cells expressing a temperature-sensitive mutant of the E1 ubiquitin-activating enzyme that, when grown at nonpermissive temperatures, accumulated HIF $\alpha$ under both normoxic and hypoxic conditions. Using so-called "far Western blots," his group showed that pVHL could bind directly to HIF $\alpha$ unless the HIF $\alpha$ was derived from cells exposed to hypoxia or iron chelators. Additionally, both groups demonstrated that a cellular factor was required for the posttranslational modification of HIF $\alpha$, as pVHL only recognized recombinant HIF after incubation with vertebrate cell lysates. A systematic mutation analysis of the minimal pVHL-binding domain of HIF $\alpha$ zeroed in on a proline residue, $\operatorname{Pro}^{564}$, which was conserved in human, Xenopus, Drosophila, and C. elegans HIF $\alpha$ proteins. Mass spectrometric analysis confirmed that $\mathrm{Pro}^{564}$ was hydroxylated. Importantly, a hydroxyproline substitution at $\mathrm{Pro}^{564}$ promoted the interaction of HIF-1 $\alpha$ with pVHL. Follow-up studies by the Kaelin and Ratcliffe groups showed that the hydroxyproline inserts into a gap within the pVHL hydrophobic core within a site that is a hotspot for tumorigenic mutations $(83,84)$. A second prolyl hydrox- ylation site, $\mathrm{Pro}^{402}$, which mediates the interaction of HIF $\alpha$ with pVHL, was identified by the Ratcliffe group a few months later (85). These data revealed that prolyl-4-hydroxylase activity was necessary to promote the interaction between HIF $\alpha$ and pVHL.

The well-studied prolyl hydroxylases at that time, which modify collagen, required $\mathrm{Fe}^{2+}$, ascorbate, molecular oxygen, and 2-oxoglutarate (2-OG, also known as $\alpha$-ketoglutarate) (86). These enzymes split molecular oxygen, using one atom to add a hydroxyl group to a target protein and the other to react with 2-OG, resulting in the generation of succinate and $\mathrm{CO}_{2}$. Ratcliffe and colleagues determined that the prolyl hydroxylase activity mediating HIF $\alpha$ hydroxylation also required these cofactors and that HIF was induced by the 2-OG analog dimethyloxalylglycine (DMOG). Through a combination of structurally informed prediction and candidate test- 
ing, Ratcliffe and his collaborator Christopher Schofield identified the dioxygenase EGL-9 as the enzyme responsible for hydroxylating the HIF $\alpha$ ortholog in C. elegans. Further, they identified a set of mammalian HIF prolyl hydroxylases (PHD1, -2, and -3; also known as EglN2, EglN1, and EglN3, respectively) that mediate hydroxylation of human HIF $\alpha$. Moreover, the activity of these enzymes was modulated by graded hypoxia, iron chelation, and $\mathrm{Co}^{2}$, as well as the 2-OG analog DMOG, mirroring the in vivo characteristics of HIF regulation (87). Rick Bruick and Steve McKnight identified these same three enzymes, after similar studies that began with the Drosophila ortholog (88).

Prolyl hydroxylation has a profound effect on HIF stability and activity, making the PHDs potential targets for pharmacological mimicking of the effects of hypoxia. The Kaelin group had also been working to identify HIF $\alpha$ PHDs and, using biochemical approaches, identified PHD2, which has emerged as the workhorse member of the family (89). In collaboration with Joan and Ron Conaway, Kaelin's group purified PHD2 and demonstrated that some small molecules designed to inhibit the related collagen prolyl hydroxylases, including selected iron chelators and 2-OG antagonists, also inhibited the activity of PHD2 (89). Moreover, treatment of cultured cells with these inhibitors stabilized HIF-1 $\alpha$, increased expression of VEGF (89), and induced EPO in mice, including mice made anemic by partial nephrectomy (90). In collaboration with Christopher Schofield, the Ratcliffe group also developed and tested different analogs of the PHD cofactor 2-OG, which stabilized HIF $\alpha$ (91). These studies established PHDs as bona fide pharmacological targets for HIF regulation. Given the growing role of HIF signaling in human disease, many such inhibitors have been developed in the past decade (92). Notably, Josef Prchal, Frank Lee, and others have linked genetic variants of PHD2, HIF $2 \alpha$, and VHL to familial polycythemia and high-altitude adaptation. Therefore, there is genetic validation in humans as well as in multiple model organisms that ties prolyl hydroxylation to oxygen sensing (93-95).

\section{A second oxygen-mediated HIF regulatory pathway}

By 2001, it was clear that HIF signaling can be induced in any cell type under hypoxic conditions and that it plays a critical role in the response to hypoxia through transcriptional activation of genes encoding proteins that either increase oxygen availability or mediate adaptive responses to intracellular oxygen deprivation. Upon the return of normal oxygen levels, oxygen-dependent binding of pVHL mediates the destruction of the HIF $\alpha$ subunit, terminating the response to hypoxia. Additionally, the C-terminal domains of HIF $\alpha$ subunits were known to contain regulatory domains $(41,42)$, which bind transcriptional coactivators, including CBP, p300, steroid receptor coactivator-1 (SRC1), and transcriptional intermediary factor-1 (TIF1) (96-98). Ratcliffe, Semenza, and others had shown that the C-terminal transactivation domains were regulated by oxygen, but this regulation influenced transcriptional activity independently of protein stability $(41,42)$.

In order to understand the regulation of the transactivation domains, the Semenza group conducted a yeast two-hybrid screen to identify proteins that interact with HIF-1 to modulate its biological activity. They identified and characterized a protein that they named factor inhibiting HIF-1 (FIH-1), which negatively regulates the function of the HIF C-terminal transactivation domain (99). They also found that FIH-1 binds to pVHL and that pVHL can function as a transcriptional corepressor that inhibits HIF-1 $\alpha$ transactivation function by recruiting histone deacetylases, thereby closing down the chromatin.

In 2002, Murray Whitelaw and colleagues showed that an asparagine residue in the C-terminal transactivation domain of HIF was hydroxylated under normoxia, but that the modification was not present under hypoxia. Asparagine hydroxylation was also prevented by iron chelators or inhibitors of 2-OGdependent dioxygenases (100). Shortly thereafter, both the collaborating Schofield and Ratcliffe laboratories and the Whitelaw group showed that FIH-1 is an iron- and 2-OG-dependent dioxygenase that hydroxylates HIF- $1 \alpha$ on an asparagine residue, thereby inactivating one of its two transactivation domains (101-103).

The identification of the prolyl and asparginyl hydroxylation events revealed a dual regulatory system of HIF activity (Figure 2) involving two oxygen-dependent hydroxylases: a PHD (most commonly PHD2) and FIH-1 (104). Both HIF $\alpha$ and HIF $\beta$ are constitutively produced, but HIF $\alpha$ is only stable and active under hypoxic conditions (around 1\% $\mathrm{pO}_{2}$ ). As oxygen levels rise, FIH-1, which has activity at lower oxygen levels than does PHD2 (105, 106), becomes active and hydroxylates an asparagine residue in the C-terminal transactivation domain of $\mathrm{HIF} \alpha$, preventing interaction with transcriptional coactivators and thereby partially abrogating $\mathrm{HIF} \alpha$ transcriptional activity (as FIH-1 does not inhibit the $\mathrm{N}$-terminal transactivation domain). As oxygen levels continue to increase, PHD2 becomes active and hydroxylates one (or both) of two prolines on HIFa. Hydroxylation of either proline promotes the interaction of HIF $\alpha$ with the pVHL E3 ubiquitin ligase complex (107), resulting in ubiquitination and subsequent proteasomal degradation. Thus, these hydroxylation events allow cells to tightly control responses to alterations in oxygen levels, only allowing for HIF accumulation and transcriptional activity under the appropriate environmental conditions (108).

\section{An expanding role for HIF in physiology and disease}

The discovery of the HIF pathway not only unveiled a new signaling mechanism mediated by oxygen, but also demonstrated that every cell in the body is capable of sensing and responding to oxygen levels. Kaelin, Ratcliffe, and Semenza have all worked to identify new roles for the pathway and to delineate the mechanisms by which HIF signaling is regulated in a given context. At the cellular level, HIF signaling has a profound effect on metabolism, allowing cells to switch from the oxygen-consuming TCA cycle to glycolysis (109). Additionally, HIF signaling contributes to cell fate decisions, including differentiation, senescence, and apoptosis (110-115). At the tissue level, HIF signaling is involved in the devel- 
opment and maintenance of numerous organs and tissues, including those in the cardiovascular, skeletal, and immune systems (116-118). Further, HIF has been shown to play a critical role in mucosal barrier functions and inflammation (119, 120). "It really has become a situation where I assume that HIF is involved in a given process until proven otherwise, because in so many contexts this pathway is important," said Semenza.

HIF-signaling pathways have been implicated in a variety of diseases states, with HIF playing a beneficial or a detrimental role, depending on the context. HIF signaling has been shown to mediate protective responses in diseases characterized by impaired tissue oxygenation and inflammation, such as coronary artery disease (CAD) (121-124), peripheral arterial disease (PAD) (125127), wound healing (128-130), organ transplant rejection $(131,132)$, and colitis (133-135). In contrast, HIF signaling might be maladaptive in other disease states, including hereditary erythrocytosis (136), pulmonary arterial hypertension (137-139), chronic ischemic cardiomyopathy $(140,141)$, and obstructive sleep apnea $(142,143)$.

HIF signaling plays complex role in cancer (144-146). Hypoxia and expression of HIF in tumors are associated with poor prognosis and have been shown to promote tumor angiogenesis, epithelial-to-mesenchymal transition, stem cell maintenance, invasion and metastasis, therapy resistance, and induction of metabolic alterations (147-149). The role of HIF in cancer has best been illustrated in the context of pVHL-defective kidney cancers. In this setting, HIF-2, rather than its better-studied cousin HIF-1, appears to the be the main culprit (150-157). The identification of HIF-2 as a driving force in kidney cancer helped to motivate and accelerate the successful development of drugs that inhibit the HIF-responsive growth factor VEGF for the treatment of this disease (145). Delineation of the pathways and factors that interact with HIF in a specific disease context has and will continue to help identify therapeutic strategies centered on HIF signaling.

Given its role in so many different disease states, a number of therapies targeting the HIF-signaling pathway are under development, with several therapeutic modalities advancing to latestage clinical trials. Since PHD inhibitors stabilize HIF $\alpha$, they cause increased HIF signaling. Such drugs could potentially be used in disease states such as anemia, in which HIF signaling is beneficial, or to protect against ischemic injury in CAD and PAD (158). Conversely, in diseases in which HIF signaling is detrimental, HIFa inhibitors may be beneficial. For example, a direct HIF inhibitor is currently in phase II clinical trials for kidney cancer (159), while drugs that indirectly downregulate $\mathrm{HIF}-1 \alpha$, including the cardiac glycoside digoxin (160), are currently in clinical trials for various forms of cancer.

\section{Coda}

Each of these researchers approached this essential biological question in a slightly different way, based on their area of specialty: Kaelin from oncology, Ratcliffe from nephrology, and Semenza from medical genetics. Since their initial discoveries, they have all continued to examine the mechanisms by which oxygen sensing impacts human physiology and disease. William Kaelin is currently a professor in the Department of Medicine and associate director of Basic Science at the Dana-Farber Institute, Harvard Medical School, where he and his team study the function of specific tumor-suppressor genes, including $V H L$. Peter Ratcliffe is the clinical research director at the Francis Crick Institute, director of the Target Discovery Institute and the Oxford Hypoxia Biology Laboratory at the University of Oxford, and a member of the Ludwig Institute for Cancer Research. His current research explores mechanisms of oxygen sensing mediated by 2-OG oxygenases, as well as the oncogenic mechanisms mediated by HIF signaling. Gregg Semenza is the C. Michael Armstrong Professor of Genetic Medicine and director of the vascular program at the Institute for Cell Engineering at the Johns Hopkins University School of Medicine, where his research group investigates oxygen homeostasis and HIF signaling in ischemic cardiovascular disease and cancer.

As Kaelin told the JCI, "in order to make big advances in science, you need to ask big questions. When you say the question out loud, it should sound a little audacious." These three physician-scientists became interested in pursuing one of the most audacious of questions: what are the mechanisms that underlie oxygen sensing in animals? The answer to that question has expanded our understanding of many different aspects of biology, ranging from metazoan evolution to cancer biology, and underscores the importance of research focused on the most basic of scientific questions.

\section{Jillian H. Hurst}

1. Viault FG. Sur l'augmentation considérable du nombre des globules rouges dans le sang chez les habitants des hauts plateaux de l'Amérique du Sud. C R Acad Sci Paris. 1890;111:917-918.

2. FitzGerald MP. The Changes in the Breathing and the Blood at Various High Altitudes. Philos Trans R Soc Lond Ser B Contain Pap Biol. 1913;203:351-371. http://www.jstor.org/stable/92005. Accessed August, 23, 2016.

3. FitzGerald MP. Further Observations on the Changes in the Breathing and the Blood at Various High Altitudes. Proc R Soc Lond Ser B Contain Pap Biol. 1914;88(602):248-258. http://www.jstor. org/stable/80707. Accessed August 23, 2016.

4. Miyake T, Kung CK, Goldwasser E. Purification of human erythropoietin. J Biol Chem. 1977;252(15):5558-5564.

5. Jacobs K, et al. Isolation and characterization of genomic and cDNA clones of human erythropoietin. Nature. 1985;313(6005):806-810.

6. Lin FK, et al. Cloning and expression of the human erythropoietin gene. Proc Natl Acad Sci U S A. 1985;82(22):7580-7584.

7. Bauer C, Kurtz A. Oxygen sensing in the kidney and its relation to erythropoietin production. Annu Rev Physiol. 1989;51:845-856.

8. Beru N, McDonald J, Lacombe C, Goldwasser E. Expression of the erythropoietin gene. Mol Cell Biol. 1986;6(7):2571-2575.

9. Bondurant MC, Koury MJ. Anemia induces accumulation of erythropoietin mRNA in the kidney and liver. Mol Cell Biol. 1986;6(7):2731-2733

10. Koury ST, Bondurant MC, Koury MJ, Semenza GL. Localization of cells producing erythropoietin in murine liver by in situ hybridization. Blood. 1991;77(11):2497-2503.

11. Koury MJ, Bondurant MC, Graber SE, Sawyer ST. Erythropoietin messenger RNA levels in developing mice and transfer of 125I-erythropoietin by the placenta. J Clin Invest. 1988;82(1):154-159.

12. Schuster SJ, Wilson JH, Erslev AJ, Caro J. Physiologic regulation and tissue localization of renal erythropoietin messenger RNA. Blood. 1987;70(1):316-318.

13. Semenza GL, Traystman MD, Gearhart JD, Antonarakis SE. Polycythemia in transgenic mice expressing the human eryth- 
ropoietin gene. Proc Natl Acad Sci U S A. 1989;86(7):2301-2305.

14. Semenza GL, Dureza RC, Traystman MD, Gearhart JD, Antonarakis SE. Human erythropoietin gene expression in transgenic mice: multiple transcription initiation sites and cis-acting regulatory elements. Mol Cell Biol. 1990;10(3):930-938.

15. Semenza GL, Koury ST, Nejfelt MK, Gearhart JD, Antonarakis SE. Cell-type-specific and hypoxia-inducible expression of the human erythropoietin gene in transgenic mice. Proc Natl Acad Sci U S A. 1991;88(19):8725-8729.

16. Semenza GL, Nejfelt MK, Chi SM, Antonarakis SE. Hypoxia-inducible nuclear factors bind to an enhancer element located 3' to the human erythropoietin gene. Proc Natl Acad Sci U S A. 1991;88(13):5680-5684.

17. Ratcliffe PJ, Jones RW, Phillips RE, Nicholls LG, Bell JI. Oxygen-dependent modulation of erythropoietin mRNA levels in isolated rat kidneys studied by RNase protection. J Exp Med. 1990;172(2):657-660.

18. Tan CC, Eckardt KU, Ratcliffe PJ. Organ distribution of erythropoietin messenger RNA in normal and uremic rats. Kidney Int. 1991;40(1):69-76.

19. Tan CC, Eckardt KU, Firth JD, Ratcliffe PJ. Feedback modulation of renal and hepatic erythropoietin mRNA in response to graded anemia and hypoxia. Am J Physiol. 1992; 263(3 Pt 2):F474-F481.

20. Pugh CW, Tan CC, Jones RW, Ratcliffe PJ. Functional analysis of an oxygen-regulated transcriptional enhancer lying 3' to the mouse erythropoietin gene. Proc Natl Acad Sci U S A. 1991;88(23):10553-10557.

21. Maxwell PH, Pugh CW, Ratcliffe PJ. Inducible operation of the erythropoietin 3' enhancer in multiple cell lines: evidence for a widespread oxygen-sensing mechanism. Proc Natl Acad Sci U S A. 1993;90(6):2423-2427.

22. Pugh CW, Ebert BL, Ebrahim O, Ratcliffe PJ. Characterisation of functional domains within the mouse erythropoietin 3' enhancer conveying oxygen-regulated responses in different cell lines. Biochim Biophys Acta. 1994;1217(3):297-306.

23. Bauer C, Koch KM, Scigalla P, Wieczorek L, eds. Erythropoietin: molecular physiology and clinical applications. New York, New York, USA: Marcel Dekker; 1993.

24. Wang GL, Semenza GL. General involvement of hypoxia-inducible factor 1 in transcriptional response to hypoxia. Proc Natl Acad Sci US A. 1993;90(9):4304-4308.

25. Wang GL, Semenza GL. Characterization of hypoxia-inducible factor 1 and regulation of DNA binding activity by hypoxia. J Biol Chem. 1993;268(29):21513-21518.

26. Nagao M, Ebert BL, Ratcliffe PJ, Pugh CW. Drosophila melanogaster SL2 cells contain a hypoxically inducible DNA binding complex which recognises mammalian HIF-binding sites. FEBS Lett. 1996;387(2-3):161-166.

27. Wang GL, Semenza GL. Purification and characterization of hypoxia-inducible factor 1 . J Biol Chem. 1995;270(3):1230-1237.
28. Semenza GL, Rue EA, Iyer NV, Pang MG, Kearns WG. Assignment of the hypoxiainducible factor 1alpha gene to a region of conserved synteny on mouse chromosome 12 and human chromosome 14q. Genomics. 1996;34(3):437-439.

29. Wiener CM, Booth G, Semenza GL. In vivo expression of mRNAs encoding hypoxiainducible factor 1. Biochem Biophys Res Commun. 1996;225(2):485-488.

30. Ema M, Taya S, Yokotani N, Sogawa K, Matsuda Y, Fujii-Kuriyama Y. A novel bHLH-PAS factor with close sequence similarity to hypoxia-inducible factor 1alpha regulates the VEGF expression and is potentially involved in lung and vascular development. Proc Natl Acad Sci U S A. 1997;94(9):4273-4278.

31. Flamme I, Fröhlich T, von Reutern M, Kappel A, Damert A, Risau W. HRF, a putative basic helix-loop-helix-PAS-domain transcription factor is closely related to hypoxia-inducible factor-1 alpha and developmentally expressed in blood vessels. Mech Dev. 1997;63(1):51-60.

32. Hogenesch JB, et al. Characterization of a subset of the basic-helix-loop-helix-PAS superfamily that interacts with components of the dioxin signaling pathway. J Biol Chem. 1997;272(13):8581-8593.

33. Tian H, McKnight SL, Russell DW. Endothelia PAS domain protein 1 (EPAS1), a transcription factor selectively expressed in endothelial cells. Genes Dev. 1997;11(1):72-82.

34. Gu YZ, Moran SM, Hogenesch JB, Wartman L, Bradfield CA. Molecular characterization and chromosomal localization of a third alphaclass hypoxia inducible factor subunit, HIF3alpha. Gene Expr. 1998;7(3):205-213.

35. Iyer NV, Leung SW, Semenza GL. The human hypoxia-inducible factor 1alpha gene: HIF1A structure and evolutionary conservation. Genomics. 1998;52(2):159-165.

36. Bacon NC, et al. Regulation of the Drosophila bHLH-PAS protein Sima by hypoxia: functional evidence for homology with mammalian HIF-1 alpha. Biochem Biophys Res Commun. 1998;249(3):811-816.

37. Jiang H, Guo R, Powell-Coffman JA. The Caenorhabditis elegans hif-1 gene encodes a bHLH-PAS protein that is required for adaptation to hypoxia. Proc Natl Acad Sci U S A. 2001;98(14):7916-7921.

38. Wood SM, Gleadle JM, Pugh CW, Hankinson $\mathrm{O}$, Ratcliffe PJ. The role of the aryl hydrocarbon receptor nuclear translocator (ARNT) in hypoxic induction of gene expression. Studies in ARNT-deficient cells. J Biol Chem. 1996;271(25):15117-15123.

39. Forsythe JA, et al. Activation of vascular endothelial growth factor gene transcription by hypoxia-inducible factor 1. Mol Cell Biol. 1996;16(9):4604-4613.

40. Jiang BH, Rue E, Wang GL, Roe R, Semenza GL. Dimerization, DNA binding, and transactivation properties of hypoxia-inducible factor 1 . J Biol Chem. 1996;271(30):17771-17778.

41. Pugh CW, O’Rourke JF, Nagao M, Gleadle JM, Ratcliffe PJ. Activation of hypoxiainducible factor-1; definition of regulatory domains within the alpha subunit. J Biol Chem. 1997;272(17):11205-11214.

42. Jiang BH, Zheng JZ, Leung SW, Roe R, Semenza GL. Transactivation and inhibitory domains of hypoxia-inducible factor 1alpha. Modulation of transcriptional activity by oxygen tension. J Biol Chem. 1997;272(31):19253-19260.

43. Firth JD, Ebert BL, Pugh CW, Ratcliffe PJ. Oxygen-regulated control elements in the phosphoglycerate kinase 1 and lactate dehydrogenase A genes: similarities with the erythropoietin 3' enhancer. Proc Natl Acad Sci U S A. 1994;91(14):6496-6500.

44. Ebert BL, Firth JD, Ratcliffe PJ. Hypoxia and mitochondrial inhibitors regulate expression of glucose transporter-1 via distinct Cis-acting sequences. J Biol Chem. 1995;270(49):29083-29089.

45. Semenza GL, Roth PH, Fang HM, Wang GL. Transcriptional regulation of genes encoding glycolytic enzymes by hypoxia-inducible factor 1. J Biol Chem. 1994;269(38):23757-23763.

46. Semenza GL, et al. Hypoxia response elements in the aldolase A, enolase 1, and lactate dehydrogenase A gene promoters contain essential binding sites for hypoxia-inducible factor 1 . J Biol Chem. 1996;271(51):32529-32537.

47. Ebert BL, Gleadle JM, O'Rourke JF, Bartlett SM, Poulton J, Ratcliffe PJ. Isoenzyme-specific regulation of genes involved in energy metabolism by hypoxia: similarities with the regulation of erythropoietin. Biochem J. 1996; 313(Pt 3):809-814.

48. Gleadle JM, Ebert BL, Firth JD, Ratcliffe PJ. Regulation of angiogenic growth factor expression by hypoxia, transition metals, and chelating agents. Am J Physiol. 1995; 268(6 Pt 1):C1362-C1368.

49. Iyer NV, et al. Cellular and developmental control of $\mathrm{O} 2$ homeostasis by hypoxia-inducible factor 1 alpha. Genes Dev. 1998;12(2):149-162.

50. Latif $\mathrm{F}$, et al. Identification of the von Hippel-Lindau disease tumor suppressor gene. Science. 1993;260(5112):1317-1320.

51. Folkman J. The role of angiogenesis in tumor growth. Semin Cancer Biol. 1992;3(2):65-71.

52. Iliopoulos O, Kibel A, Gray S, Kaelin WG. Tumour suppression by the human von Hippel-Lindau gene product. Nat Med. 1995;1(8):822-826.

53. Kibel A, Iliopoulos O, DeCaprio JA, Kaelin WG. Binding of the von Hippel-Lindau tumor suppressor protein to Elongin B and C. Science. 1995;269(5229):1444-1446.

54. Duan DR, et al. Characterization of the VHL tumor suppressor gene product: localization, complex formation, and the effect of natural inactivating mutations. Proc Natl Acad Sci U S A. 1995;92(14):6459-6463.

55. Duan DR, et al. Inhibition of transcription elongation by the VHL tumor suppressor protein. Science. 1995;269(5229):1402-1406.

56. Ohh M, et al. Synthetic peptides define critical contacts between elongin $\mathrm{C}$, elongin $\mathrm{B}$, and the von Hippel-Lindau protein. J Clin Invest. 1999;104(11):1583-1591.

57. Stebbins CE, Kaelin WG, Pavletich NP. Structure of the VHL-ElonginC-ElonginB complex: 
implications for VHL tumor suppressor function. Science. 1999;284(5413):455-461.

58. Levy AP, Levy NS, Wegner S, Goldberg MA. Transcriptional regulation of the rat vascular endothelial growth factor gene by hypoxia. J Biol Chem. 1995;270(22):13333-13340.

59. Liu Y, Cox SR, Morita T, Kourembanas S. Hypoxia regulates vascular endothelial growth factor gene expression in endothelial cells. Identification of a 5' enhancer. Circ Res. 1995;77(3):638-643.

60. Iliopoulos O, Levy AP, Jiang C, Kaelin WG, Goldberg MA. Negative regulation of hypoxia-inducible genes by the von Hippel-Lindau protein. Proc Natl Acad Sci U S A. 1996;93(20):10595-10599.

61. Maxwell PH, et al. Hypoxia-inducible factor-1 modulates gene expression in solid tumors and influences both angiogenesis and tumor growth. Proc Natl Acad Sci U S A. 1997;94(15):8104-8109.

62. Jiang BH, Agani F, Passaniti A, Semenza GL. V-SRC induces expression of hypoxia-inducible factor 1 (HIF-1) and transcription of genes encoding vascular endothelial growth factor and enolase 1: involvement of HIF-1 in tumor progression. Cancer Res. 1997;57(23):5328-5335.

63. Zhong H, et al. Increased expression of hypoxia inducible factor-1alpha in rat and human prostate cancer. Cancer Res. 1998;58(23):5280-5284.

64. Talks KL, et al. The expression and distribution of the hypoxia-inducible factors HIF-1alpha and HIF-2alpha in normal human tissues, cancers, and tumor-associated macrophages. Am J Pathol. 2000;157(2):411-421.

65. Kallio PJ, Pongratz I, Gradin K, McGuire J, Poellinger L. Activation of hypoxia-inducible factor 1alpha: posttranscriptional regulation and conformational change by recruitment of the Arnt transcription factor. Proc Natl Acad Sci U S A. 1997;94(11):5667-5672.

66. Salceda S, Caro J. Hypoxia-inducible factor 1alpha (HIF-1alpha) protein is rapidly degraded by the ubiquitin-proteasome system under normoxic conditions. Its stabilization by hypoxia depends on redox-induced changes. J Biol Chem. 1997;272(36):22642-22647.

67. Huang LE, Gu J, Schau M, Bunn HF. Regulation of hypoxia-inducible factor 1alpha is mediated by an O2-dependent degradation domain via the ubiquitin-proteasome pathway. Proc Natl Acad Sci U S A. 1998;95(14):7987-7992.

68. Sutter CH, Laughner E, Semenza GL. Hypoxiainducible factor 1alpha protein expression is controlled by oxygen-regulated ubiquitination that is disrupted by deletions and missense mutations. Proc Natl Acad Sci U S A. 2000;97(9):4748-4753.

69. Lonergan KM, et al. Regulation of hypoxiainducible mRNAs by the von Hippel-Lindau tumor suppressor protein requires binding to complexes containing elongins $\mathrm{B} / \mathrm{C}$ and $\mathrm{Cul} 2$. Mol Cell Biol. 1998;18(2):732-741.

70. Jackson PK. Cell cycle: cull and destroy. Curr Biol. 1996;6(10):1209-1212.

71. Kamura T, et al. Rbx1, a component of the VHL tumor suppressor complex and SCF ubiquitin ligase. Science. 1999;284(5414):657-661.
72. Iwai K, et al. Identification of the von Hippel-lindau tumor-suppressor protein as part of an active E3 ubiquitin ligase complex. Proc Natl Acad Sci U S A. 1999;96(22):12436-12441.

73. Lisztwan J, Imbert G, Wirbelauer C, Gstaiger M, Krek W. The von Hippel-Lindau tumor suppressor protein is a component of an E3 ubiquitin-protein ligase activity. Genes Dev 1999;13(14):1822-1833.

74. Maxwell PH, et al. The tumour suppressor protein VHL targets hypoxia-inducible factors for oxygen-dependent proteolysis. Nature. 1999;399(6733):271-275.

75. Ohh M, et al. Ubiquitination of hypoxia-inducible factor requires direct binding to the betadomain of the von Hippel-Lindau protein. Nat Cell Biol. 2000;2(7):423-427.

76. Kallio PJ, Wilson WJ, O’Brien S, Makino Y, Poellinger L. Regulation of the hypoxiainducible transcription factor 1alpha by the ubiquitin-proteasome pathway.J Biol Chem. 1999;274(10):6519-6525.

77. Cockman ME, et al. Hypoxia inducible factor-alpha binding and ubiquitylation by the von Hippel-Lindau tumor suppressor protein. J Biol Chem. 2000;275(33):25733-25741.

78. Kamura T, Sato S, Iwai K, Czyzyk-Krzeska M, Conaway RC, Conaway JW. Activation of HIF1alpha ubiquitination by a reconstituted von Hippel-Lindau (VHL) tumor suppressor complex. Proc Natl Acad Sci U S A. 2000;97(19):10430-10435.

79. Wang GL, Semenza GL. Desferrioxamine induces erythropoietin gene expression and hypoxia-inducible factor 1 DNA-binding activity: implications for models of hypoxia signal transduction. Blood. 1993;82(12):3610-3615.

80. Jaakkola P, et al. Targeting of HIF-alpha to the von Hippel-Lindau ubiquitylation complex by O2-regulated prolyl hydroxylation. Science. 2001;292(5516):468-472.

81. Ivan M, et al. HIFalpha targeted for VHLmediated destruction by proline hydroxylation: implications for $\mathrm{O} 2$ sensing. Science. 2001;292(5516):464-468

82. Yu F, White SB, Zhao Q, Lee FS. HIF-1alpha binding to VHL is regulated by stimulus-sensitive proline hydroxylation. Proc Natl Acad Sci U S A. 2001;98(17):9630-9635.

83. Min JH, Yang H, Ivan M, Gertler F, Kaelin WG, Pavletich NP. Structure of an HIF-1alpha -pVHL complex: hydroxyproline recognition in signaling. Science. 2002;296(5574):1886-1889.

84. Hon WC, et al. Structural basis for the recognition of hydroxyproline in HIF-1 alpha by pVHL. Nature. 2002;417(6892):975-978.

85. Masson N, Willam C, Maxwell PH, Pugh CW, Ratcliffe PJ. Independent function of two destruction domains in hypoxia-inducible factor-alpha chains activated by prolyl hydroxylation. EMBO J. 2001;20(18):5197-5206.

86. Myllyharju J, Kivirikko KI. Characterization of the iron- and 2-oxoglutarate-binding sites of human prolyl 4-hydroxylase. EMBO J. 1997;16(6):1173-1180.

87. Epstein AC, et al. C. elegans EGL-9 and mammalian homologs define a family of dioxygenases that regulate HIF by prolyl hydroxylation.
Cell. 2001;107(1):43-54

88. Bruick RK, McKnight SL. A conserved family of prolyl-4-hydroxylases that modify HIF. Science. 2001;294(5545):1337-1340.

89. Ivan $\mathrm{M}$, et al. Biochemical purification and pharmacological inhibition of a mammalian prolyl hydroxylase acting on hypoxiainducible factor. Proc Natl Acad Sci U S A. 2002;99(21):13459-13464.

90. Safran M, et al. Mouse model for noninvasive imaging of HIF prolyl hydroxylase activity: assessment of an oral agent that stimulates erythropoietin production. Proc Natl Acad Sci U S A. 2006;103(1):105-110.

91. Mole DR, et al. 2-oxoglutarate analogue inhibitors of HIF prolyl hydroxylase. Bioorg Med Chem Lett. 2003;13(16):2677-2680.

92. Chan MC, Holt-Martyn JP, Schofield CJ, Ratcliffe PJ. Pharmacological targeting of the HIF hydroxylases--A new field in medicine development. Mol Aspects Med. 2016;47-48:54-75.

93. Gordeuk VR, et al. Congenital disorder of oxygen sensing: association of the homozygous Chuvash polycythemia VHL mutation with thrombosis and vascular abnormalities but not tumors. Blood. 2004;103(10):3924-3932.

94. Song D, et al. Defective Tibetan PHD2 binding to $\mathrm{p} 23$ links high altitude adaption to altered oxygen sensing. J Biol Chem. 2014;289(21):14656-14665.

95. Beall CM, et al. Natural selection on EPAS1 (HIF2alpha) associated with low hemoglobin concentration in Tibetan highlanders. Proc Natl Acad Sci U S A. 2010;107(25):11459-11464.

96. Arany Z, et al. An essential role for p300/CBP in the cellular response to hypoxia. Proc Natl Acad Sci U S A. 1996;93(23):12969-12973.

97. Carrero P, Okamoto K, Coumailleau P, O'Brien S, Tanaka H, Poellinger L. Redox-regulated recruitment of the transcriptional coactivators CREB-binding protein and SRC-1 to hypoxia-inducible factor 1alpha. Mol Cell Biol. 2000;20(1):402-415.

98. Ema M, et al. Molecular mechanisms of transcription activation by HLF and HIF1alpha in response to hypoxia: their stabilization and redox signal-induced interaction with $\mathrm{CBP} /$ p300. EMBO J. 1999;18(7):1905-1914.

99. Mahon PC, Hirota K, Semenza GL. FIH-1: a novel protein that interacts with HIF-1alpha and VHL to mediate repression of HIF-1 transcriptional activity. Genes Dev. 2001;15(20):2675-2686.

100.Lando D, Peet DJ, Whelan DA, Gorman JJ, Whitelaw ML. Asparagine hydroxylation of the HIF transactivation domain a hypoxic switch. Science. 2002;295(5556):858-861.

101. Lando D, Peet DJ, Gorman JJ, Whelan DA, Whitelaw ML, Bruick RK. FIH- 1 is an asparaginyl hydroxylase enzyme that regulates the transcriptional activity of hypoxia-inducible factor. Genes Dev. 2002;16(12):1466-1471.

102. Hewitson KS, et al. Hypoxia-inducible factor (HIF) asparagine hydroxylase is identical to factor inhibiting HIF (FIH) and is related to the cupin structural family. J Biol Chem. 2002;277(29):26351-26355.

103.Elkins JM, et al. Structure of factor-inhibiting 
hypoxia-inducible factor (HIF) reveals mechanism of oxidative modification of HIF-1 alpha. J Biol Chem. 2003;278(3):1802-1806.

104.Berra E, Benizri E, Ginouvès A, Volmat V, Roux $\mathrm{D}$, Pouysségur J. HIF prolyl-hydroxylase 2 is the key oxygen sensor setting low steady-state levels of HIF-1alpha in normoxia. EMBO J. 2003;22(16):4082-4090.

105.Flashman E, Hoffart LM, Hamed RB, Bollinger JM, Krebs C, Schofield CJ. Evidence for the slow reaction of hypoxia-inducible factor prolyl hydroxylase 2 with oxygen. FEBS J. 2010;277(19):4089-4099.

106.Tarhonskaya $\mathrm{H}$, et al. Kinetic investigations of the role of factor inhibiting hypoxia-inducible factor (FIH) as an oxygen sensor. J Biol Chem. 2015;290(32):19726-19742.

107.Chan DA, Sutphin PD, Yen SE, Giaccia AJ. Coordinate regulation of the oxygendependent degradation domains of hypoxiainducible factor 1 alpha. Mol Cell Biol. 2005;25(15):6415-6426.

108. Masson N, Ratcliffe PJ. HIF prolyl and asparaginyl hydroxylases in the biological response to intracellular O(2) levels. J Cell Sci. 2003; 116(Pt 15):3041-3049.

109.Semenza GL. Regulation of metabolism by hypoxia-inducible factor 1. Cold Spring Harb Symp Quant Biol. 2011;76:347-353.

110.Semenza GL. Hypoxia. Cross talk between oxygen sensing and the cell cycle machinery. Am J Physiol Cell Physiol. 2011;301(3):C550-C552.

111. Semenza GL. Dynamic regulation of stem cell specification and maintenance by hypoxiainducible factors. Mol Aspects Med. 2016; 47-48:15-23.

112. Hubbi ME, Semenza GL. Regulation of cell proliferation by hypoxia-inducible factors. Am J Physiol Cell Physiol. 2015;309(12):C775-C782.

113. Ratcliffe PJ. Understanding hypoxia signalling in cells--a new therapeutic opportunity? Clin Med (Lond). 2006;6(6):573-578.

114. Hubbi ME, et al. A nontranscriptional role for HIF- $1 \alpha$ as a direct inhibitor of DNA replication. Sci Signal. 2013;6(262):ra10.

115. Hubbi ME, et al. Cyclin-dependent kinases regulate lysosomal degradation of hypoxia-inducible factor $1 \alpha$ to promote cell-cycle progression. Proc Natl Acad Sci U S A. 2014;111(32):E3325-3334.

116. Bishop T, Ratcliffe PJ. HIF hydroxylase pathways in cardiovascular physiology and medicine. Circ Res. 2015;117(1):65-79.

117. Pugh CW, Ratcliffe PJ. Regulation of angiogenesis by hypoxia: role of the HIF system. Nat Med. 2003;9(6):677-684.

118. Kaelin WG, Ratcliffe PJ. Oxygen sensing by metazoans: the central role of the HIF hydroxylase pathway. Mol Cell. 2008;30(4):393-402

119. Taylor CT, Doherty G, Fallon PG, Cummins EP. Hypoxia-dependent regulation of inflammatory pathways in immune cells. J Clin Invest. 2016;126(10):3716-3724.

120. Glover LE, Lee JS, Colgan SP. Oxygen metabolism and barrier regulation in the intestinal mucosa. J Clin Invest. 2016;126(10):3680-3688.

121. Hlatky MA, et al. Polymorphisms in hypoxia inducible factor 1 and the initial clinical pre- sentation of coronary disease. Am Heart J. 2007;154(6):1035-1042.

122. Resar JR, et al. Hypoxia-inducible factor 1alpha polymorphism and coronary collaterals in patients with ischemic heart disease. Chest. 2005;128(2):787-791.

123. Cai Z, Luo W, Zhan H, Semenza GL. Hypoxiainducible factor 1 is required for remote ischemic preconditioning of the heart. Proc Natl Acad Sci U S A. 2013;110(43):17462-17467.

124. Olenchock BA, et al. EGLN1 Inhibition and Rerouting of $\alpha$-Ketoglutarate Suffice for Remote Ischemic Protection. Cell. 2016;164(5):884-895.

125.Bosch-Marce M, et al. Effects of aging and hypoxia-inducible factor-1 activity on angiogenic cell mobilization and recovery of perfusion after limb ischemia. Circ Res. 2007;101(12):1310-1318.

126. Loinard C, et al. Inhibition of prolyl hydroxylase domain proteins promotes therapeutic revascularization. Circulation. 2009;120(1):50-59.

127. Rey S, et al. Synergistic effect of HIF-1alpha gene therapy and HIF-1-activated bone marrow-derived angiogenic cells in a mouse model of limb ischemia. Proc Natl Acad Sci US A. 2009;106(48):20399-20404.

128. Botusan IR, et al. Stabilization of HIF-1alpha is critical to improve wound healing in diabetic mice. Proc Natl Acad Sci U S A. 2008;105(49):19426-19431

129. Mace KA, Yu DH, Paydar KZ, Boudreau N, Young DM. Sustained expression of Hif-1alpha in the diabetic environment promotes angiogenesis and cutaneous wound repair. Wound Repair Regen. 2007;15(5):636-645.

130.Zhang $\mathrm{X}$, et al. Impaired angiogenesis and mobilization of circulating angiogenic cells in HIF-1alpha heterozygous-null mice after burn wounding. Wound Repair Regen . 2010;18(2):193-201.

131. Jiang X, et al. Adenovirus-mediated HIF$1 \alpha$ gene transfer promotes repair of mouse airway allograft microvasculature and attenuates chronic rejection. J Clin Invest. 2011;121(6):2336-2349.

132. Bernhardt WM, et al. Donor treatment with a PHD-inhibitor activating HIFs prevents graft injury and prolongs survival in an allogenic kidney transplant model. Proc Natl Acad Sci U S A. 2009;106(50):21276-21281.

133. Karhausen J, Furuta GT, Tomaszewski JE, Johnson RS, Colgan SP, Haase VH. Epithelial hypoxia-inducible factor- 1 is protective in murine experimental colitis. J Clin Invest. 2004;114(8):1098-1106

134. Cummins EP, et al. The hydroxylase inhibitor dimethyloxalylglycine is protective in a murine model of colitis. Gastroenterology. 2008;134(1):156-165.

135. Hirota SA, et al. Hypoxia-inducible factor signaling provides protection in Clostridium difficile-induced intestinal injury. Gastroenterology. 2010;139(1):259-269.e3.

136. Yoon D, Ponka P, Prchal JT. Hypoxia. 5. Hypoxia and hematopoiesis. Am J Physiol Cell Physiol. 2011;300(6):C1215-C1222.
137. Shimoda LA, Semenza GL. HIF and the lung: role of hypoxia-inducible factors in pulmonary development and disease. Am J Respir Crit Care Med. 2011;183(2):152-156.

138. Brusselmans K, et al. Heterozygous deficiency of hypoxia-inducible factor-2alpha protects mice against pulmonary hypertension and right ventricular dysfunction during prolonged hypoxia. J Clin Invest. 2003;111(10):1519-1527.

139. Bonnet S, et al. An abnormal mitochondrialhypoxia inducible factor-1alpha-Kv channel pathway disrupts oxygen sensing and triggers pulmonary arterial hypertension in fawn hooded rats: similarities to human pulmonary arterial hypertension. Circulation. 2006;113(22):2630-2641.

140. Moslehi J, et al. Loss of hypoxia-inducible factor prolyl hydroxylase activity in cardiomyocytes phenocopies ischemic cardiomyopathy. Circulation. 2010;122(10):1004-1016.

141. Bekeredjian R, et al. Conditional HIF-1alpha expression produces a reversible cardiomyopathy. PLoS One. 2010;5(7):e11693.

142. Belaidi E, Morand J, Gras E, Pépin JL, Godin-Ribuot D. Targeting the ROS-HIF-1endothelin axis as a therapeutic approach for the treatment of obstructive sleep apnea-related cardiovascular complications [published online ahead of print August 3, 2016]. Pharmacol Ther. doi:10.1016/j. pharmthera.2016.07.010.

143.Semenza GL, Prabhakar NR. Neural regulation of hypoxia-inducible factors and redox state drives the pathogenesis of hypertension in a rodent model of sleep apnea. J Appl Physiol. 2015;119(10):1152-1156

144. Ratcliffe PJ. Oxygen sensing and hypoxia signalling pathways in animals: the implications of physiology for cancer. J Physiol (Lond). 2013;591(8):2027-2042.

145. Shen C, Kaelin WG. The VHL/HIF axis in clear cell renal carcinoma. Semin Cancer Biol. 2013;23(1):18-25.

146. Kim W, Kaelin WG. The von Hippel-Lindau tumor suppressor protein: new insights into oxygen sensing and cancer. Curr Opin Genet Dev. 2003;13(1):55-60.

147. Kaelin WG. Cancer and altered metabolism: potential importance of hypoxia-inducible factor and 2-oxoglutarate-dependent dioxygenases. Cold Spring Harb Symp Quant Biol. 2011;76:335-345.

148. Semenza GL. The hypoxic tumor microenvironment: A driving force for breast cancer progression. Biochim Biophys Acta. 2016;1863(3):382-391.

149. Semenza GL. Cancer-stromal cell interactions mediated by hypoxia-inducible factors promote angiogenesis, lymphangiogenesis, and metastasis. Oncogene. 2013;32(35):4057-4063.

150.Kondo K, Klco J, Nakamura E, Lechpammer M, Kaelin WG. Inhibition of HIF is necessary for tumor suppression by the von Hippel-Lindau protein. Cancer Cell. 2002;1(3):237-246.

151. Kondo K, Kim WY, Lechpammer M, Kaelin WG. Inhibition of HIF2alpha is sufficient to suppress pVHL-defective tumor growth. PLoS 
Biol. 2003;1(3):E83.

152.Shen C, et al. Genetic and functional studies implicate HIF $1 \alpha$ as a $14 \mathrm{q}$ kidney cancer suppressor gene. Cancer Discov. 2011;1(3):222-235.

153.Zimmer M, Doucette D, Siddiqui N, Iliopoulos O. Inhibition of hypoxia-inducible factor is sufficient for growth suppression of VHL-/tumors. Mol Cancer Res. 2004;2(2):89-95.

154. Maranchie JK, Vasselli JR, Riss J, Bonifacino JS, Linehan WM, Klausner RD. The contribution of VHL substrate binding and HIF1-alpha to the phenotype of VHL loss in renal cell car- cinoma. Cancer Cell. 2002;1(3):247-255.

155. Raval RR, et al. Contrasting properties of hypoxia-inducible factor 1 (HIF-1) and HIF-2 in von Hippel-Lindau-associated renal cell carcinoma. Mol Cell Biol. 2005;25(13):5675-5686.

156. Kim WY, et al. Failure to prolyl hydroxylate hypoxia-inducible factor alpha phenocopies VHL inactivation in vivo. $E M B O J$. 2006;25(19):4650-4662.

157. Gordan JD, et al. HIF-alpha effects on c-Myc distinguish two subtypes of sporadic VHLdeficient clear cell renal carcinoma.
Cancer Cell. 2008;14(6):435-446.

158. Maxwell PH, Eckardt KU. HIF prolyl hydroxylase inhibitors for the treatment of renal anaemia and beyond. Nat Rev Nephrol. 2016;12(3):157-168

159. Rogers JL, et al. Development of inhibitors of the PAS-B domain of the HIF- $2 \alpha$ transcription factor. J Med Chem. 2013;56(4):1739-1747.

160.Zhang H, et al. Digoxin and other cardiac glycosides inhibit HIF-1alpha synthesis and block tumor growth. Proc Natl Acad Sci U S A. 2008;105(50):19579-19586. 